BBA 55392

\title{
THE EFFECT OF ACYL-GROUP COMPOSITION ON THE RATE OF ACYLTRANSFERASE-CATALYZED SYNTHESIS OF LECITHIN
}

\author{
ALAN E. BRANDT AND W. E. M, LANDS \\ Department of Biological Chemistry, The University of Michigan, Ann Arbor, Mich. (U.S.A.) \\ (Received July $7^{\text {th }}, 1967$ )
}

SUMMARY

The acyltransferase rates for 66 combinations of substrates ( 6 acylglycerolphosphorylcholines and II acylcoenzyme A derivatives) were measured using an enzyme preparation from pig liver. The results support the earlier findings with ratliver enzymes showing that the position to be acylated was more significant than the composition of fatty acids in the I-acylglycerolphosphorylcholine.

\section{INTRODUCTION}

In I963, LANDS AND MERKL' showed that I-acylglycerol-3-phosphorylcholine containing either saturated or unsaturated acids would be preferentially esterified with linoleic rather than stearic acid. Considering this and subsequent work the specificity of the acyl-CoA: acylglycerol-3-phosphorylcholine acyltransferases in rat liver appears particularly sensitive to the character of the acyl radical in the thio ester $^{2-4}$, but not to the acyl portion of the acylglycerol-3-phosphorylcholine. The two acylglycerol-3-phosphorylcholine preparations tested contained quite different contents of saturated and unsaturated acids, but were nevertheless mixtures as so often occurs in nature. Furthermore, the overall reaction included the action of acid: $\mathrm{CoA}$ ligase under conditions that hopefully would not infuence the observed specificity. We have therefore prepared synthetic I-acylglycerol-3-phosphorylcholine derivatives with different acyl chains to test the specificity of the acyltransferases under defined conditions more appropriate to a kinetic analysis. The results confirm that the principal specificity is for the acid being transferred rather than the acid present in the phospholipid substrate.

\section{EXPERIMENTAL}

\section{Preparation of lecithin from egg yolk}

Egg yolk ( $8 \mathrm{~kg}$ obtained from University of Michigan Food Service) was homogenized with 481 of acetone (technical grade). The homogenate was filtered and the Abbreviation: DTNB, 5*5'dithio-bis-(2-nitrobenzoate). 
precipitate was placed in a large jar $(45 \mathrm{~cm} \times 30 \mathrm{~cm})$ and was dissolved in $19.21 \mathrm{chlo-}$ roform-methanol $(2: \mathrm{I}, \mathrm{v} / \mathrm{v})$. The entire solution was stirred with a piece of glass tubing connected to a stream of $\mathrm{N}_{2}$. The solution was washed with 9.61 of distilled water and was allowed to stand until the layers separated (there was also a layer of protein at the interface). The aqueous supernatant was removed and the chloroform layer was siphoned from beneath the protein. Lipids were washed from the protein layer with chloroform and combined with the first chloroform solution. A chromatographic column $(9.5 \mathrm{~cm} \times 90 \mathrm{~cm})$ was prepared by slurrying $\mathrm{I} 2 \mathrm{lbs}$ of alumina in chloroform. The solution of egg-yolk lipids was placed directly onto the column which was eluted with chloroform-methanol $(9: \mathrm{I}, \mathrm{v} / \mathrm{v})$. The fractions collected from the column were checked by thin-layer chromatography to determine the components eluted. Plates were prepared with Silica Gel G (Brinkman) at a thickness of $0.33 \mathrm{~mm}$, and devcloped in a solvent of chloroform methanol acetic acid-water $65: 25: 8: 4$, by vol.). The fractions containing the lecithin were partially evaporated, and the lecithin was precipitated by pouring the resulting syrup into 4 gallons of reagent grade acetone. The supernatant acetone was removed and the lecithin precipitate was washed by resuspending it in acetone. The lecithin precipitate was removed, dissolved in chloroform - methanol $(9: \mathrm{I}, \mathrm{v} / \mathrm{V})$ and stored at $4^{\circ}$. Yield: $34 \mathrm{~g}$ phospholipid $/ \mathrm{kg}$ of which $23 \mathrm{~g} / \mathrm{kg}$ of starting egg yolk was lecithin. The lecithin fraction gave only one spot on thin-layer chromatography plates in 2 different solvent systems (chloroform-methanol-acetic acid-water $(65: 25: 8: 4$, by vol.); chloroform-methanolwater $(65: 25: 4$, by vol.) indicating the absence of ethanolamine phosphoglyceride, sphingomyelin and monoacylglycerol-3-phosphorylcholine.

\section{Preparation of (glycerol-3-phosphorylcholine $)_{2}\left(\mathrm{CdCl}_{2}\right)_{3}(\mathrm{ref} .5)$}

A solution containing I Io $g$ of egg lecithin was taken to dryness and the lipid was dissolved in $550 \mathrm{ml}$ of methanol. Sodium methoxide $(200 \mathrm{ml}, 2 \mathrm{M})$ was added to the solution which was constantly stirred. The reaction was allowed to proceed for 5 min after which the reaction mixture was poured over $27.5 \mathrm{~g}$ of $\mathrm{IRC}-50\left(\mathrm{H}^{+}\right)$resin premoistened with $\mathrm{I}$ oo $\mathrm{ml}$ of water. The resin was stirred and then removed by centrifugation. The resin was washed twice with $50 \mathrm{ml}$ of methanol, and the washes were combined with the first methanol solution. The solvent was removed and the residue was dissolved in 21 of chloroform-methanol $(9: I, V / v)$ and washed twice with $55 \mathrm{ml}$ of water. The combined aqueous layers were diluted with 4.41 of absolute ethanol. A saturated solution of $\mathrm{CdCl}_{2} \cdot 2.5 \mathrm{H}_{2} \mathrm{O}$ in $95 \%$ ethanol was added until no further precipitation occurred. The $\mathrm{CdCl}_{2}$ derivative of glycerol-3-phosphorylcholine, (glycerol-3-phosphorylcholine $)_{2}\left(\mathrm{CdCl}_{3}\right)_{3}$, was stored over $\mathrm{P}_{2} \mathrm{O}_{5}$. Yield: $78.5 \mathrm{~g}(50 \%$ on a molar basis).

\section{Acid chlorides}

Lauroyl, myristoyl, palmitoyl, and stearoyl chlorides were obtained from Eastman Kodak. Linoleoyl chloride was prepared in the following manner: $50 \mathrm{~g}$ of linoleic acid (Hormel Institute, $99 \%$ purity) was placed in a round-bottom flask fitted with a reflux condensor. The complete system was flushed thoroughly with $\mathrm{N}_{2}$. Oxalyl chloride $(25 \mathrm{ml})$ was added and the system was evacuated several times with a mild vacuum to remove the $\mathrm{HCl}$ produced. After $\mathrm{HCl}$ was no longer evolved, $25 \mathrm{ml}$ of oxalyl chloride were added and the mixture was heated to reflux gently. The mixture was 
allowed to stand $3 \mathrm{~h}$ at room temperature. Unreacted oxalyl chloride and $\mathrm{HCl}$ were removed on a rotary evaporator under vacuum at $50^{\circ}$. The linoleoyl chloride was dissolved in hexane, and ice was added. When the ice melted, the aqueous layer was removed and the hexane layer was washed again with ice water. The hexane was placed over anhydrous $\mathrm{Na}_{2} \mathrm{SO}_{4}$ and allowed to stand for $0.5 \mathrm{~h}$. The hexane solution was decanted and stored over fresh anhydrous $\mathrm{Na}_{2} \mathrm{SO}_{4}$ under $\mathrm{N}_{2}$ at $-20^{\circ}$. Hexane was removed (using a rotary evaporator) immediately before the acid chloride was used to prepare dilinoleoylglycerolphosphorylcholine. The yield was $100 \%$ based on quantitative gas chromatography using an internal standard of methyl pentadeconate.

\section{Preparation of specific lecithins}

The method employed was a modification of the procedure developed by BAER AND BUCHNEA ${ }^{\text {. }}$.

\section{I,2-Dilauroylglycerol-3-phosphorylcholine}

Superbrite glass beads (50 ml) and II $\mathrm{g}$ of dry (glycerol-3-phosphorylcholine) ${ }_{2}$ $\left(\mathrm{CdCl}_{2}\right)_{3}$ were placed in a dry $250-\mathrm{ml}$ round-bottom flask; $20 \mathrm{ml}$ of lauroyl chloride in $20 \mathrm{ml}$ of carbon tetrachloride (reagent grade) were added and washed in with $20 \mathrm{ml}$ of carbon tetrachloride, and then II $\mathrm{ml}$ of pyridine in $30 \mathrm{ml}$ of carbon tetrachloride was added. The round-bottom flask was fitted with a ground glass fitting equipped with a stopcock. The reaction mixture was shaken vigorously at $37^{\circ}$ for $24 \mathrm{~h}$ with occasional venting. The reaction mixture was transferred to a thick-walled centrifuge bottle and centrifuged; the supernatant was decanted and the precipitate was washed 3 times with $50 \mathrm{ml}$ of chloroform; the combined supernatant solutions were taken to a syrupy residue and dissolved in $50 \mathrm{ml}$ of chloroform. The chloroform solution was centrifuged, and the precipitate was washed twice with $5 \mathrm{ml}$ of chloroform. The chloroform washes were taken to dryness and placed under vacuum $(0.5 \mathrm{~mm}$ of $\mathrm{Hg})$ for $\mathrm{I} 2 \mathrm{~h}$. The residue was dissolved in $50 \mathrm{ml}$ of chloroform-methanol $(2: \mathrm{I}, \mathrm{v} / \mathrm{v})$ and washed with water until the washes gave no precipitate upon addition of $\mathrm{AgNO}_{3}$. The solvent was removed from the chloroform layer and the residue was taken up in diethyl ether-benzene $(\mathrm{I}: \mathrm{I}, \mathrm{v} / \mathrm{v})$. This solution was placed on a column of $60 \mathrm{~g}$ of silicic acid. The column was successively washed with $\mathrm{r} 20 \mathrm{ml}$ of diethyl ether-benzene $(\mathrm{I}: \mathrm{I}, \mathrm{v} / \mathrm{v})$, $200 \mathrm{ml}$ of diethyl ether-ethanol $(\mathrm{I}: \mathrm{I}, \mathrm{v} / \mathrm{v}), 200 \mathrm{ml}$ of ethanol-methanol $(\mathrm{I}: \mathrm{I}, \mathrm{v} / \mathrm{v})$, and methanol until all $x$-lauroylglycerol 3 phosphorylcholine was removed from the column. Thin-layer chromatography was used to check fractions for phospholipid content. Those fractions containing only dilauroylglycerol-3-phosphorylcholine were combined; the remaining material was a mixture of mono- and dilauroylglycerol-3phosphorylcholine. Yield: pure dilauroylglycerol-3-phosphorylcholine, ro.7 mmoles; mixed mono- and dilauroylglycerol-3-phosphorylcholine, 2.24 mmoles; total (based on phosphate) $65 \%$.

\section{I,2-Dimyristoylglycerol-3-phosphorylcholine}

The preparation was the same as that used for the dilauroyl derivative except that myristoyl chloride (O.I mole) was used and the reaction mixture was incubated for $45 \mathrm{~h}$ at $37^{\circ}$. The separation of the reaction products was accomplished in the same manner as with dilauroylglycerol-3-phosphorylcholine. Yield: dimyristoylglycerol-3- 
phosphorylcholine, $6.6 \mathrm{r}$ mmoles; mixed mono- and dimyristoylglycerol-3-phosphorylcholine, 3.64 mmoles; total (based on phosphate) $5 \mathrm{r} \%$.

\section{I,2-Dipalmitoylglycerol-3-phosphorylcholine}

This was prepared in the same manner as dilauroylglycerol-3-phosphorylcholine with the following exception: 0.084 moles palmitoyl chloride were used. The reaction mixture was incubated at $37^{\circ}$ for $40 \mathrm{~h}$. Yield: dipalmitoylglycerol-3-phosphorylcholine, 2.92 mmoles; mixed mono- and dipalmitoylglycerol-3-phosphorylcholine, 3.68 mmoles; total (based on phosphate) $32 \%$.

\section{I,2-Distearoylglycerol-3-phosphorylcholine}

The preparation was the same as for dilauroylglycerol-3-phosphorylcholine except $8.25 \mathrm{~g}$ of (glycerol-3-phosphorylcholine $)_{2}\left(\mathrm{CdCl}_{y}\right)_{3}$, 90 mmoles stearoyl chloride and $8.3 \mathrm{ml}$ pyridine were used. The mixture was incubated at $37^{\circ}$ for $80 \mathrm{~h}$. Yield: distearoylglycerol-3-phosphorylcholine, I.47 mmole; mixed mono- and distearoylglycerol-3-phosphorylcholine, I.37 mmole; total (based on phosphate) I $9 \%$.

\section{r,2-Dioleoylglycerol-3-phosphorylcholine}

This was prepared in the same manner as dilauroylglycerol-3-phosphorylcholine except Io $\mathrm{g}$ (glycerol-3-phosphorylcholine $)_{2}\left(\mathrm{CdCl}_{2}\right)_{3}$ and 86 mmoles of oleoyl chloride were used. The reaction mixture was incubated at $37^{\circ}$ for $20 \mathrm{~h}$. The reaction products were separated in the same manner. Yield: dioleoylglycerol-3-phosphorylcholine, 0.80 mmole; mixed mono- and dioleoylglycerol-3-phosphorylcholine, 0.02 mmole; total (based on phosphate) $4.5 \%$.

\section{I,2-Dilinoleoylglycerol-3-phosphorylcholine}

Prepared in the same manner as dilauroylglycerol-3-phosphorylcholine except I 80 mmoles linoleoyl chloride was used. All reagents and containers were flushed with $\mathrm{N}_{2}$ to remove oxygen. The $250-\mathrm{ml}$ round-bottom flask was wrapped in aluminum foil while it was incubated in the dark at room temperature for $15 \mathrm{~h}$. The products of the reaction were handled in the same manner as dilauroylglycerol-3-phosphorylcholine except all solvents and containers were flushed with $\mathrm{N}_{2}$. Yield: dilinoleoylglycerol-3phosphorylcholine, 0.78 mmole; mixed mono- and dilinoleoylglycerol-3-phosphorylcholine, 2.03 mmoles; total (based on phosphate) $14 \%$.

\section{Preparation of $x$-acylglycerol-3-phosphorylcholine derivatives}

Distearoylglycerol-3-phosphorylcholine $(530 \mu$ moles $)$ was suspended in $100 \mathrm{ml}$ of ether, $0.25 \mathrm{ml}$ of $0.0 \mathrm{I} \mathrm{M} \mathrm{CaCl}_{2}$ and $36.3 \mathrm{mg}$ lyophilized Crotalus adamanteus venom in $3.3 \mathrm{ml}$ of $\mathrm{O} . \mathrm{I} \mathrm{M}$ Tris chloride $(\mathrm{pH} 7.4$ ) were added followed by an additional roo $\mathrm{ml}$ of ether. The reaction mixture was shaken vigorously and allowed to stand $\mathrm{I} 2 \mathrm{~h}$ during which time the I-stearoylglycerol-3-phosphorylcholine precipitated. The supernatant ether was removed and the I-stearoylglycerol-3-phosphorylcholine was dissolved in Io $\mathrm{ml}$ of chloroform after removal of residual ether. A chromatographic column of $50 \mathrm{~g}$ of silicic acid was prepared in chloroform. The crude $\mathrm{x}$-stearoylglycerol3-phosphorylcholine preparation in chloroform was placed on the column and the column was washed with roo $\mathrm{ml}$ of chloroform, $400 \mathrm{ml}$ of chloroform-methanol $(3: \mathrm{r}$, $\mathrm{v} / \mathrm{v})$, and $700 \mathrm{ml}$ of methanol. The eluted fractions were checked with thin-layer 


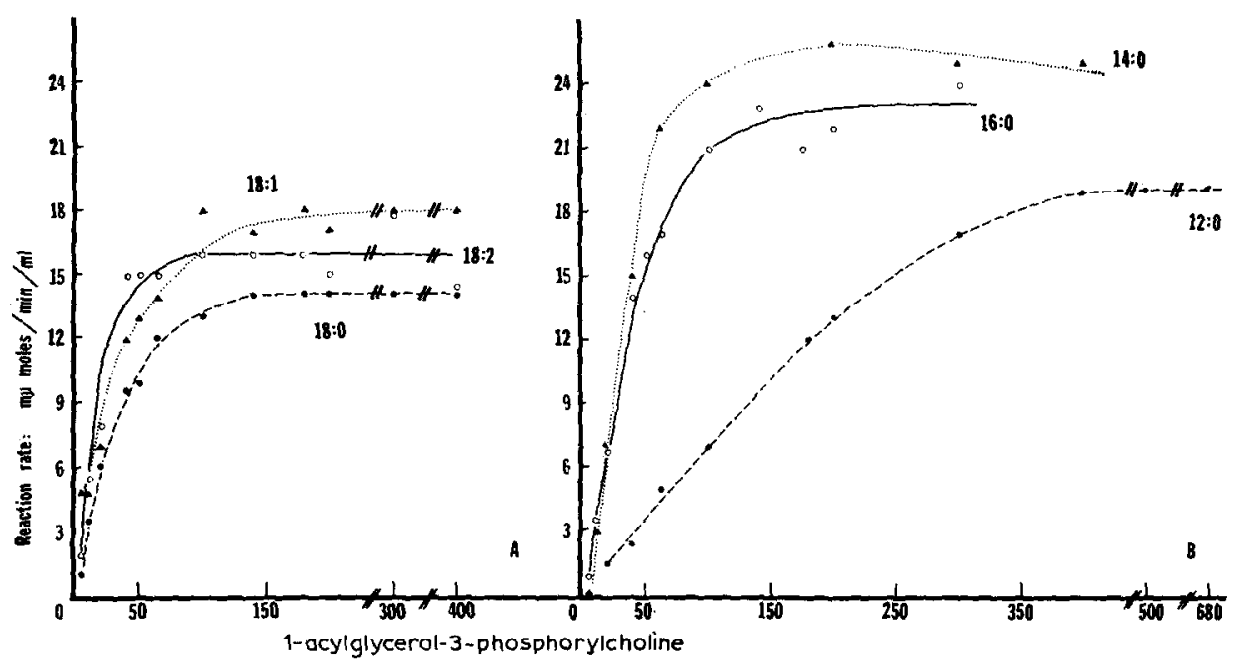

Fig. I. Influence of acylglycerol-3-phosphorylcholine concentration on the acyltransferase initial velocities. A: $-\cdots-\longrightarrow, \mathbf{I} 8: 0 ; \mathbf{A} \cdots \cdots \cdots, \mathbf{I} 8: 1 ; 0-0, \mathbf{I} 8: 2 . \mathbf{B}$ : I $4: 0 ; 0-\cdots, 16: 0$.

chromatography (silicic acid $<200$ mesh, chloroform-methanol-water $(65: 25: 4$, by vol.). Fractions containing I-stearoylglycerol-3-phosphorylcholine were combined, evaporated to dryness and dissolved and stored at $0^{\circ}$ in chloroform-methanol (2:I, $\mathrm{v} / \mathrm{v}$ ). The yield, based on phosphate was $97 \%$ and the ratio of ester to phosphate in the product was I.05.

With the exception of I-linoleoylglycerol-3-phosphorylcholine, other I-acylglycerol-3-phosphorylcholines were prepared in the same manner as I-lauroylglycerol-3-phosphorylcholine. These results are summarized in Table I. In the preparation of I-linoleoylglycerol-3-phosphorylcholine, the precipitate was washed twice with

TABLE I

PREPARATION OF I-ACYLGLYCEROL-3-PHOSPHORYLCHOLINE DERIVATIVES

\begin{tabular}{lccc}
\hline $\begin{array}{l}\text { I-Acylglycerol } \\
\text { 3-phosphorylcholine }\end{array}$ & $\begin{array}{l}\text { Diacyl precursor } \\
\text { (pmoles) }\end{array}$ & $\begin{array}{c}\text { Yield } \\
(\%)\end{array}$ & Ester:phosphate \\
\hline Lauroyl & 950 & 98 & 0.82 \\
Myristoyl & 1200 & 95 & 0.93 \\
Palmitoyl & 840 & 98 & 0.97 \\
Stearoyl & 530 & 97 & 1.05 \\
Oleoyl & 170 & 97 & 0.83 \\
Linoleoyl & 78 & 93 & 0.96 \\
\hline
\end{tabular}

$5 \mathrm{ml}$ of diethyl ether. The I-linoleoylglycerol-3-phosphorylcholine was taken up in chloroform-methanol $(2: I, v / v)$ from which oxygen had been removed by bubbling $\mathrm{N}_{2}$ through it, and the solution was stored at $-20^{\circ}$. The yield based on phosphate was $93 \%$, a trace of dilinoleoylglycerol-3-phosphorylcholine impurity was observed on thin-layer chromatography; ester: phosphate $=0.96$.

The I-acylglycerol-3-phosphorylcholine had the following fatty acid compositions based on quantitalive gas-liquid chromatography: I-lauroylglycerol-3-phosphorylcholine: $12: 0,97.8 \%$; I4:0, 0.5\%; 16:0, 1.7\%; r-myristoylglycerol-3-phosphoryl- 
choline: I2:0, I. $2 \%$; I4:0, $95.7 \%$; $6: 0,2.6 \% ;$ I $8: 0,0.6 \%$; I-palmitoylglycerol-3phosphorylcholine: I $4: 0$, I.2\%; I6:0, $96 \cdot 2 \% ;$ I $8: 0,2.6 \%$; I-stearnylglycerol-3-phosphorylcholine: $x 6: 0,4.0 \%$; $8: 0,96.0 \%$; I-oleoylglycerol-3-phosphorylcholine: $16: 0$, $6.7 \% ; \mathrm{I} 6: \mathrm{I}, \quad 9.0 \% ; \mathrm{I} 8: \mathrm{I}, 84.3 \%$; I-linoleoylglycerol-3-phosphorylcholine: I 7:0, $0.4 \% ; 18: 2,99.6 \%$. Gas-liquid chromatographic analyses were performed in the presence of an internal standard as described by LANDS AND HART ${ }^{\mathbf{1 0}}$. Phosphorus was determined by the method of BARTLETT?.

\section{Determination of acyltransferase reaction rates}

The acyltransferase reaction was followed continuously using the internal colorimetric indicator, 5,5'-dithio-bis-(2-nitrobenzoate) (DTNB), for liberated sulfhydryl groups and measuring the absorbance at $4 \mathrm{I} 3 \mathrm{~m} \mu$. A typical reaction mixture contained: $0.8 \mathrm{ml}$ of o.I M Tris chloride buffer ( $\mathrm{pH} 7.4$ ), o.I $\mathrm{ml}$ of o.or M DTNB, $30 \mathrm{~m} \mu \mathrm{moles}$ acyl-CoA, o.I $8 \mathrm{mg}$ microsomal protein from pig liver and $200 \mathrm{~m} \mu$ moles I-acylglycerol3-phosphorylcholine in o.I $\mathrm{ml}$ of $0 . \mathrm{I} \mathrm{M}$ Tris chloride ( $\mathrm{pH} \mathrm{7.4)} \mathrm{(400} \mathrm{m \mu moles} \mathrm{of} \mathrm{the}$ lauroyl derivatives were used).

\section{RESULTS}

The low $K_{m}$ values $\left(<\mathrm{IO}^{-5} \mathrm{M}\right.$ ) reported for the acyl-CoA derivatives, ${ }^{1,2}$ were confirmed in preliminary experiments. All subsequent work was done with thiol ester concentrations $\left(3 \cdot 10^{-5} \mathrm{M}\right)$ considered to be capable of saturating the enzyme. The initial acyltransfer velocities increased with increasing concentrations of the acylglycerol-3-phosphorylcholine derivatives up to Io- $15^{\cdot 10^{-5}} \mathrm{M}$ (except the lauroyl derivative at $40-50 \cdot 10^{-5} \mathrm{M}$ ). The plots of initial velocity versus substrate concentra-

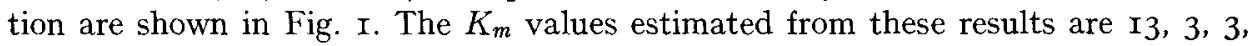
$3,2.5$ and $2 \cdot \mathrm{IO}^{-5} \mathrm{M}$ for the I2:0, I4:0, I6:0, I8:0, I8:I and I8:2 derivatives, respectively.

Acyltransferase rates obtained with different acyl-CoA and acylglycerol-3phosphorylcholine derivatives under maximal conditions are shown in Table II. The results with palmitoyl- and stearoylglycerol-3-phosphorylcholine agree with the earlier observation that I-acylglycerol-3-phosphorylcholine is acylated more rapidly with the medium-chain saturated fatty acids than with the long-chain saturated acids. This selectivity is less, however, with the lauroyl- and linoleoyl derivatives. With each acylglycerol-3-phosphorylcholine tested the overall pattern of specificity is similar to that found with the other acylglycerol-3-phosphorylcholine derivatives. In other words, the differences in acyltransfer rate observed in the horizontal rows are not as great as those seen along the vertical columns.

\section{DISCUSSION}

The difficulties encountered in earlier work of insuring both solubility of the fatty acid substrate and optimal activity of the acid: CoA ligase needed to produce the intermediate acyl-CoA are avoided in the direct spectrophotometric assay of the acyltransfer reaction. Both substrates for this reaction appear to be freely soluble at the concentrations used in this study and relatively low levels of protein are needed in each experiment. This low level (0.1 $8 \mathrm{mg} / \mathrm{ml})$ eliminates much of the non-specific 


\section{TABLE II}

\section{ACYLTRANSFERASE ACTIVITIES}

The rates are averages of four assays with the exception of the following pairs which are averages of two assays: I-I 4:0 glycerol-3-phosphorylcholine, I6: I CoA; I-16:0 glycerol-3-phosphorylcholine, I6: I CoA. The values are $\rfloor \mathrm{I} \mathrm{m} \mu \mathrm{mole} / \mathrm{min}$ per $\mathrm{mg}$ protein. Since each assay involved a continual recording of the product formed, each velocity reportcd represents a large number of recorded determinations.

\begin{tabular}{|c|c|c|c|c|c|c|}
\hline \multirow[t]{2}{*}{ Acyl-CoA } & \multicolumn{6}{|c|}{$\begin{array}{l}\text { Acyltransferase activities (mumoles/min per } m g \text { protein) } \\
I \text {-Acylglycerol-3-phosphorylcholine }\end{array}$} \\
\hline & $12: 0$ & $14: 0$ & $I 6: 0$ & $18: 0$ & $I 8: I$ & $I 8: 2$ \\
\hline $12: 0$ & $5 \cdot 7$ & Io & 9.6 & $4 \cdot 3$ & I I & $7 \cdot 3$ \\
\hline$I_{4}: 0$ & $7 \cdot 3$ & 5.6 & $5 \cdot 7$ & 1.9 & 9.6 & 5.2 \\
\hline I6:0 & 6.4 & 4.2 & 3.0 & 0.77 & 8.9 & 5.2 \\
\hline I $8: 0$ & 6.4 & 3.8 & 0.93 & 0 & 6.9 & 4.8 \\
\hline $20: 0$ & 0 & 0 & 0 & 0 & o & o \\
\hline I $6: \mathrm{I}$ & 5.8 & 8.4 & 7.1 & $4 \cdot 5$ & 6.4 & $4 \cdot 7$ \\
\hline I 8: I & 9.6 & I 7 & I3 & 9.4 & I I & $7 \cdot 5$ \\
\hline I $8: 2$ & I 8 & 20 & I 5 & $I_{4}$ & $2 I$ & 26 \\
\hline I $8: 3$ & 18 & 23 & Io & $\mathrm{T}_{4}$ & 20 & 20 \\
\hline $20: 3$ & 32 & 37 & 35 & $2 \mathrm{I}$ & 36 & 40 \\
\hline $20: 4$ & I 3 & I6 & I3 & IO & 13 & $2 \mathrm{I}$ \\
\hline
\end{tabular}

binding of substrate that led to the high apparent $K_{m}$ value observed earlier with about $6-7 \mathrm{mg}$ of protein per $\mathrm{ml}^{8}$. The present $K_{m}$ values for acylglycerol-3-phosphorylcholine are more in agreement with those reported by LANDS AND HART ${ }^{2}$ for liver microsomes and by STEIN, STEIN AND SHAPIRO ${ }^{\circ}$ for homogenates of rat heart. The latter workers, however, noted severe inhibition by higher concentrations of acylglycerol-3-phosphorylcholine which prevented a reliable estimate of $K_{m}$. In the present study, reciprocal plots of velocity versus substrate concentration show a slight upward curvature suggesting that the very low levels of acylglycerol-3-phosphorylcholine may not be fully effective. The non-specific binding of such a detergent as acylglycerol-3-phosphorylcholine to microsomal protein is probably unavoidable in this system. Fortunately, the acylglycerol-3-phosphorylcholine is not a particularly strong inhibitor in this system so that the enzyme can be effectively saturated with both substrates. The acyltransfer rates with $\mathrm{I} 6: 0$ and $\mathrm{I} 8: 2$ acylglycerol-3-phosphorylcholine for I 8:0 and I8:2 acyl-CoA are most appropriate for comparison with the earlier experiment ${ }^{1}$ showing that the position to be acylated was more significant than the composition of fatty acids in the acylglycerol-3-phosphorylcholine.

One of the important relationships that we wished to investigate was whether the palmitoylglycerol-3-phosphorylcholine would react more rapidly with oleate than with arachidonate. Similarly the stearoylglycerol-3-phosphorylcholine might react more rapidly with arachidonate than oleate or linoleate. Such a correlative specificity would help explain the often observed association of the two pairs of acids in naturallyoccuring phospholipids (e.g. ref. Io). The results obtained in this work indicate that the tendency for these acids to occur as pairs rather than in fully random combinations cannot be cxplaincd by acyltransfcrase selcctivity. The common alternative explanation in such a situation would be that the two lecithins (I6:0-I8: I and I8:020:4) may be formed from metabolically separate pools of fatty acids.

The character of the acyl group of the 6 different acylglycerol-3-phosphorylcholines had very little effect on the acyltransfer rates for the various unsaturated 
acyl-CoA derivatives. However, two rather unusual findings merit further consideration. First, the arachidoyl-CoA was essentially inert with all substrates tested. Second, the observed rates tend to decrease as the total carbon atoms in the fatty acids of the saturated lecithin formed increase from 26 to 38 . These "families" of lecithins would be indicated by diagonal lines in Table II. The average rates for these types are shown below:

$\begin{array}{lccccccr}\text { Carbon atoms } & 26 & 28 & 30 & 32 & 34 & 36 & 38 \\ \text { Average rate } & 8.6 & 7.2 & 5.5 & 2.2 & 0.6 & 0 & 0\end{array}$

Although the average rate has no exact physical significance, the trend in velocities seems correlated with the solubility of the product. In such a case, we must seriously consider whether the rate-limiting process in some acyltransferase reactions is the forming of the ester linkage from soluble precursors or the removal of relatively insoluble products from the active site. That problem, however, goes beyond the methods and purposes of this paper.

The results reported here for reactions catalyzed by microsomal preparations from pig liver agree with those obtained earlier with a mixed acylglycerol-3-phosphorylcholine preparation. In addition, they show specificities that are similar to those found for enzyme preparations from rat liver ${ }^{2}$. Although the general specificity patterns for acyl-CoA:acylglycerol-3-phosphorylcholine acyltransferases are similar for different animals, some differences also exist ${ }^{2}$. Further work in our laboratory is directed towards the characterization of a number of different acyltransferases that may be present.

While this manuscript was in preparation, we found that similar results were obtained by VAN DEN BOSCH et al. ${ }^{11}$.

\section{ACKNOWLEDGEMENT}

This work was supported in part by the National Institutes of Health (AM 05310).

\section{REFERENCES}

I W. E. M. Lands and I. Merke, J. Biol. Chem., 238 (I963) 898.

2 W. E. M. I.A.NDS AND P. HART, $J$. Biol. Chem., 240 (1965) I 905.

3 W. E. M. Lands, J. Am. Oil Chemists' Soc, 42 (r 965$) 465$.

4 W. E. M. Lands, M. L. Blank, L. I. NuTter aNd O. S. Privetr, Lidids. 1 (1966) 224.

5 D. J. Hanahan, Biochem. Prep., $9(1962) 55$.

6 E. Baer and D. Buchnea, Canb. J. Biookom. Physiol., 37 (r959) 953 .

7 G. R. Bartlett, J. Biol. Chem., 234 (1959) 466.

8 W. E. M. Lands, J. Biol. Chem., 235 (1960) 2233.

9 Y. Stein, O. Stein and B. Shaproo, Biochim. Biophys. Acia, 7o (1963) 33.

Io W. E. M. Lands and P. Hart, J. Am. Oil Chemists' Soc., 43 (I966) 290.

I I. Van den Bosch, L. M. G. Van Golde, H. Erbl and L. L. M. Van Deenen, Biochim. Biophys. Acta, 144 (1967) 613 .

Biochim. Biophys. Acta, $144(1967) 605-612$ 